\title{
Reviewing the Mental Health Act: delivering evidence-informed policy
}

\author{
Simon Wessely, Brynmor Lloyd-Evans, Sonia Johnson
}

There was some surprise when in 2017 the Prime Minister announced an Independent Review of the Mental Health Act for England and Wales (MHA Review). Unlike the previous review, which led to the 2007 Act, this new initiative was not driven by concerns around public safety. Aims were to address the rapidly rising rate of detentions and high rates for people from Black ethnic groups; to achieve better alignment with recent developments in human rights; and to clarify the complex interface between the MHA and the Mental Capacity Act (2005).

The MHA Review process has involved wide ranging consultation with stakeholders; intensive work in 17 different topic groups; consultation with the devolved administrations; consideration of legal issues and detailed analysis of international conventions. The active participation of service users and patients was always centre stage. It has also involved analysis of large amounts of government data, held in a variety of departments and armslength bodies. Additional scrutiny of a large academic literature ensured that whenever possible, our final recommendations were supported by best-available scientific evidence.

To help navigate this morass of data and research, the MHA Review commissioned a programme of academic research, mainly conducted by the NIHR Mental Health Policy Research Unit (MH PRU), and others including the NIHR Maudsley Biomedical Research Centre and the Exeter University Medical School. The Mental Health Policy Research Unit was established in 2017 as part of a network of Policy Research Units ${ }^{1,2}$ designed to deliver rapid research to inform evidence-based policy making. Funding and deadlines do not generally allow large-scale de novo data collection, but data synthesis, analyses of existing data sets and targeted qualitative studies can be conducted.

Commissioned research has supported the work of the Review in three main ways:

i) Understanding the nature of the challenge: obtaining fine-grained information about who is detained through analysis of anonymised health records; reviewing rates of detention and legislative systems internationally; identifying predictors of detention; and developing an explanatory model for the rising rate of detentions.

ii) Understanding the experience and perspectives of patients and carers: systematically reviewing studies of people's and their families' experience of detention; and of views on the role of the Nearest Relative.

iii) Identifying effective interventions: rapidly synthesising evidence regarding interventions to reduce detentions.

One systematic review from this programme is published ${ }^{3}$; others will follow shortly. The MHA Review has thus been informed wherever possible by research evidence: for example, 
by exploring issues not readily answered from routine data such as are more people being detained, or the same people being detained more often; and are particular legal arrangements associated with lower rates of detention internationally? A systematic review identified advance statements as currently the most promising intervention to reduce detentions: they are strongly promoted within the MHA Review report.

The work of the MH PRU in supporting the MHA Review models how researchers can work together with policy makers to provide rapid, policy-relevant research to support a major national policy review. Useful as it has proved, it has also highlighted gaps in knowledge which hamper evidence-informed policy making. Priorities for future work include: i) addressing the woeful state of routine data about compulsory admissions (which has told us little about the characteristics of those detained - essential for monitoring health equity, or about the clinical and social groups who are most frequently detained and thus priority groups for preventive intervention); ii) adding to the extremely limited evaluation of compulsory admission as an outcome in research trials (reported in less than $2 \%$ of trials identified in evidence syntheses for the MHA Review); and iii) developing evidenceinformed strategies to achieve effective scaled-up implementation of desirable interventions at national level.

Finally, we recognise that research evidence is not the only valid driver of policy-making ${ }^{4}$, and the difficulties in merging traditional research methodologies with equally powerful legal analysis, and with the views of politicians and the public, clinicians and those who have been users of the system, by definition unwillingly. In the end, as the MHA Review final report will show, it was the latter that had the most impact. As one service user told the Chair (SW) at an early meeting "I can understand looking back why I needed to be detained at that moment in my life, but what I can't understand is why it was such a needlessly unpleasant experience". Our work understanding why coercion is increasing and what might be the most effective means to prevent detention are all very well, but if we can't answer that person's question, we have failed.

1. National Institute for Health Research "Policy Research Units" (web resource) https://www.nihr.ac.uk/about-us/how-we-are-managed/our-structure/research/policy-researchunits.htm 2018 [Accessed 30/11/2018)

2. Johnson, S. "Research unit to bring evidence to forefront of mental health policy" The Mental Elf blog (web resource) https://www.nationalelfservice.net/publication-types/policy/research-unit-tobring-evidence-to-forefront-of-mental-health-policy/ 2017 [Accessed 30/11/2019]

3. Barnett,P. Matthews,H. Lloyd-Evans,B. et al. "Compulsory community treatment to reduce readmission to hospital and increase engagement with community care in people with mental illness: a systematic review and meta-analysis" The Lancet Psychiatry 2018: 5(12) 1013-1022

4. Oliver,K. Lorenc,T. Invaer,S. "New directions in evidence-based policy research: a critical analysis of the literature" Health Research Policy and Systems 2018: 12(34)

Acknowledgement Simon Wessely is the Chair of the Independent Review of the Mental Health Act. Sonia Johnson is Director, and Brynmor Lloyd-Evans is a Deputy Director of the NIHR Mental Health 
Policy Research Unit, funded through the National Institute for Health Research Policy Research Programme. The views expressed are those of the authors and not necessarily those of the NHS, the National Institute for Health Research, the Department of Health and Social Care or its arm's length bodies, and other Government Departments. 